\title{
Research on the teaching system of undergraduate logistics management major based on the concept of sustainable development

\author{
Wei Liu
}

\author{
Xiamen university of Tan Kah Kee college, Zhangzhou, China \\ liuwei568@xujc.com
}

\begin{abstract}
Keywords: Sustainable concept, Curriculum system, Practice teaching, Effective teaching.
Abstract. As the business demands changes, as well as the college entrance examination according to the professional enrollment changes, the logistics management professional teaching content and the way put forward new requirements. Based on the concept of sustainable development, this article puts forward four basic modules of undergraduate logistics management major: basic courses, development courses, cross courses and core courses. We can expand the practice teaching system, cultivate students' practical ability and innovative entrepreneurial consciousness. We can also achieve effective teaching by combining with teaching in class, team learning and network development.
\end{abstract}

\section{基于可持续理念的本科物流管理专业教学体系研究 \\ 刘威}

厦门大学嘉庚学院, 漳州, 中国

liuwei568@xujc.com

关键词：可持续理念；课程体系；实践教学；有效教学

中文摘要. 企业需求的变化, 以及高考按专业招生方式的转变, 对物流管理专业的教学内容 和方式提出了新的要求。本文基于可持续理念，提出构建本科物流管理专业课程体系四大基 本模块: 基础课程、拓展课程、交叉课程以及核心课程。拓展实践教学体系, 培养学生的实 践动手能力和创新创业意识。结合课堂讲授、团队学习和网络拓展等三种学习形式实现有效 教学。

\section{1. 引言}

物流业是支撑国民经济发展的战略性、生产性服务产业，它的健康发展得了国家政策的 大力支持。例如，2014年9月国务院印发《物流业发展中长期规划（2014-2020年）》，2015 年11月国家标准化管理委员会联合国家发展和改革委员会、工业和信息化部等部门编制了《物 流标准化中长期发展规划（2015一-2020年）》，2016年8月国家发展改革委、交通运输部等部 门印发 《推进 “互联网+” 便捷交通，促进智能交通发展的实施方案》，2017年1月商务部、 发展改革等部门制定了《商贸物流发展 “十三五” 规划》，规划期为2016-2020年等。各项政 策的推出, 对促进物流业顺利发展, 产业结构调整, 提高国民经济竞争力具有重要意义。

根据中国物流与采购联合会报道，2016年社会物流总额达到230万亿元，社会物流总费用 达到 11 万亿元。物流业的快速发展, 对物流相关人才的需求进一步扩大，对物流管理人才的 培养提出了新的挑战。

从2017年起，上海和浙江地区将首次试点，采取按专业招生的方式进行招考。同时，《教 育部2017年工作要点》中指出，“推进 “科教结合协同育人行动计划”、“校企深度合作示 
范项目, 等建设; 搭建应用型高校校企合作平台。” ${ }^{[1]}$ 新制度和政策的推行对人才培养模式 的改革和高等教育水平的提升, 提出了新的要求。

最近十年来, 随着经济的发展, 可持续教育理念得到了越来越多的重视。“教育的可持 续性” 和 “教育的可持续发展” 等术语在国外的文献中不断出现, 在高等教育, 尤其是商科 教育领域, 新的教育项目, 新的研究机构和新的教学方法不断涌现。 ${ }^{[2]}$

物流管理专业作为应用型学科, 主要培养德智体美全面发展, 具有良好的人文与科学素 养, 具有扎实的专业知识与技能, 具备良好实践能力的应用型、复合型、创新型人才。如何 有效地构建本科物流管理专业教学体系? 如何可持续地提升本科物流管理专业学生的创新能 力和创新意识? 有哪些教学的方法和技术适用于物流管理专业可持续发展? 本文重点探讨这 些亟待解决的问题。

\section{2. 可持续教育理念发展概述}

根据世界环境和发展委员会的报告，可持续性是指机构或组织通过提供资源满足当前需 求, 并使得下一代的需求不受损害, 追求的目标是，在维持当前的经济健康发展的前提下， 保证自然资源、环境资源和社会资源的充分合理地利用。可持续教育整合了三个重要维度: 经济、社会和环境。[3]

可持续教育理念在全球获得了推广，各国和地区成立了相关的机构。1987年布伦特兰报 告对教学项目进行评估, 提出教育中应推行可持续发展的理念。1990年塔乐礼宣言首次对教 学机构可持续的教学和研究进行官方表述。美国管理学会于1991年创立了组织与自然环境分 部, 自1990 年代中期开始, 联合国教科文组织开始在全球范围内推进《环境人口与可持续发 展教育项目》，中国也相继推出了中国可持续教育项目。美国于 2000 年成立了高等教育可持 续性促进协会，2002年联合国举行的可持续发展问题世界首脑会议上提出实施 “可持续发展 教育十年” 建议。欧盟在2005年提出欧盟十年教育可持续发展规划（2005-2014）。各机构不 断加强对教育, 特别是高等教育可持续性发展的引导, 提高教育者进行环境与可持续发展教 育的能力，致力于可持续教育体系的研究和教学方法的提升。

2016年联合国教科文组织发布的《教育造福人类与地球》报告指出，为了顺利实现 2030 年可持续发展议程各项全球性目标, 世界各国还需要大力发展教育。中国进入经济发展新常 态和供给侧改革的新阶段, 随着 “中国制造 2025 ”、互联网+、创新创业等政策的推进, 高等 教育也需顺应经济和社会的发展, 进行教育教学的改革。

\section{3. 本科物流管理专业教学体系设置}

在物流管理教学体系的设置方面，一些学者提出了不同的看法。Lutz和 Birou针对6个不 同国家77个学校的118门物流课程进行分析, 首次大规模的研究了本科和研究生物流课程, 本 科课程涵盖的最常见的主题包括: 物流管理导论、运输管理、库存管理、客户服务、信息技 术、物流、仓储、网络设计、物料搬运、供应链管理组织等 ${ }^{[4]}$ 。Wu和Huang 等从实践者的角 度对台湾的全球物流管理课程进行分析认为, 为了应对全球化, 要求学生能够进行整合、从 国际视角进行分析、财务绩效分析、维持好的商业和客户关系、具备较强的人际交往能力、 保持健康和了解法律法规。 ${ }^{[5]}$ Wong 和Grant认为, 本科物流课程有三个主要目标: 全面的理 解物流各项活动, 培养分析和解决各种物流问题的能力, 获得物流领域专业知识的机会。[6]

现在越来越多的公司关注物流和供应链的运作和优化, 物流管理专业结合企业需求和学 科发展的情况, 在对学生的理论知识和实践能力培养方面, 应该重点突出"厚基础、宽口径、 强能力、高素质"的培养目标。物流管理专业应用型管理人才在系统地掌握管理、经济、法律 等知识的基础上, 应掌握物流管理所需的各项核心知识和能力, 尤其是创新能力、创业能力、 深入研究解决物流问题的能力、领导能力以及具备高度的社会责任感。 


\section{1 课程体系的设计}

Gartner咨询公司发布的《Survey Analysis: Top 25 North American Supply Chain Undergraduate University Programs,2016》报告, 比较了2014年和2016年北美大学供应链管理 专业前 25 强的本科课程的开设情况, 该报告认为本科供应链学位应该获得的专业知识包括: 新产品开发和导入、生产计划、采购管理、配送管理、整合供应链、客户关系管理、财务管 理、项目管理和治理、绩效管理和分析以及战略管理等。[7]

物流管理在课程体系的设计过程中, 可以参考供应链管理专业的设置情况, 课程设计贯 穿的理念是: 通过企业资源规划系统进行整合, 关注质量管理, 全球化驱动和电子商务发展, 运用IT作为制定决策的工具, 结合环境的可持续视角。因此, 将物流管理专业课程体系设置 如下图1所示, 主要涉及基础课程、拓展课程、交叉课程以及包括采购和供应管理、生产与运 营管理、配送和客户服务、项目管理和绩效等核心课程在内的四个模块。

\subsection{1基础课程}

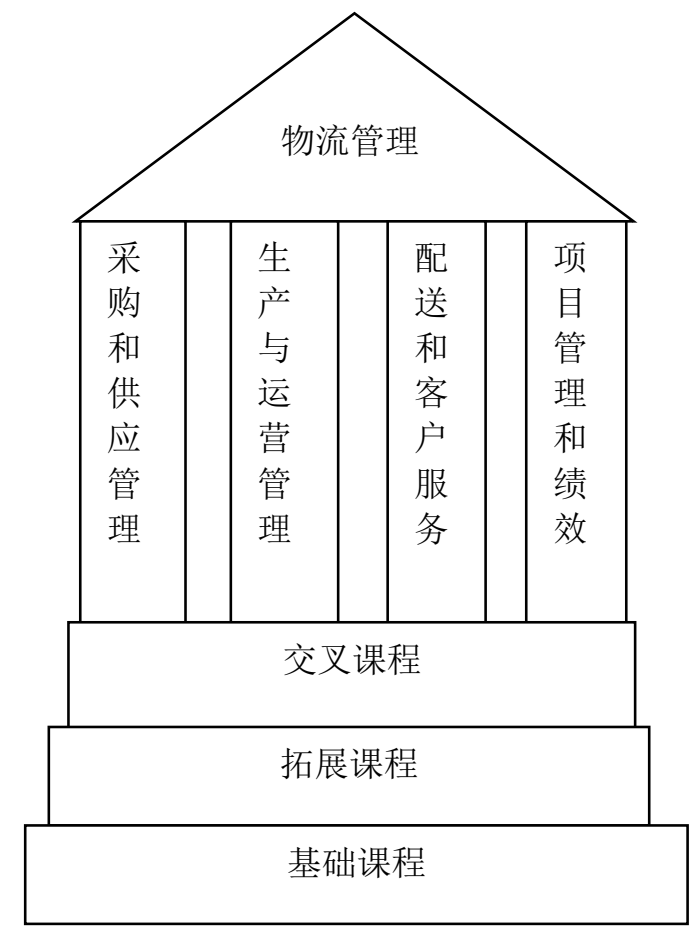

图1 物流管理专业课程体系设计

基础课程主要是商科专业必修的课程, 培养学生的计算机操作能力、英语应用能力、职 业素质以及构建商科专业基础知识体系, 课程包括: 计算机基础、大学英语、批判性思考和 写作、职业生涯规划、商务谈判和关系管理、公司社会责任和伦理、时间管理、微积分、宏 观经济学、微观经济学、概率和数理统计、会计学原理、法律基础、人力资源管理、企业领 导力管理、市场营销管理、运营管理、战略管理、国际商务管理等。

\subsection{2拓展课程}

拓展课程主要是其他专业修读的相关课程, 同时, 要求课程紧密结合业界发展趋势, 以 满足学生的个性化需求, 课程包括: 国际经济学、国际贸易实务、电子商务基础、电子商务 与物流管理、供应链金融、互联网金融、金融工程、信息系统和大数据、商务智能、计算机 程序设计、计量经济学、营销渠道管理、商业模式创新等。

\subsection{3交叉课程}

交叉课程主要是物流管理专业选修的课程，用于开拓学生的专业视野和应用方向，课程 包括: 创新创业管理、全面质量管理、数据库管理系统、物流信息系统、企业资源规划、物 流设施设备、国际运输和物流、需求计划和管理、战略供应链管理、供应链管理案例研究、 
物流与信息技术、管理决策工具、环境经济学和可持续性、能源货物和环境、运输经济学、 运输车辆管理、物流成本管理、货运代理实务、物流系统仿真等。

3.1 .4 核心课程

核心课程主要是物流管理专业必修课程，主要是培养学生的核心能力和专业素养，课程 包括：运筹学、技术创新和合作、新产品开发、采购和供应管理、生产计划和控制、项目管 理、流程管理分析和控制、绩效管理分析、运输管理、仓储和库存管理、精益管理和六西格 玛、可持续供应链管理等。

\section{2实践教学体系的构建}

实践教学注重理论和实践相结合, 是培养高素质人才的重要途径, 是提高学生动手动脑 能力的重要举措。物流管理专业应努力将各知识点与实践联系起来, 搭建实验操作、案例教 学、项目调研、课程实习、CO-OP实习、第二课堂等全方位、立体化的实践教学体系。

3.2.1实验操作

实验操作主要是讲课过程中, 将课程内容与计算机软件相结合, 设计相应的实验, 让学 生掌握软件的使用原理和方法。例如, 《计算机基础》课程采用上机操作，《概率和数理统 计》运用 R语言进行讲解, 《互联网金融》课程结合网络交易平台进行模拟, 《金融工程》 采用Excel或Matlab软件进行计算, 《信息系统和大数据》运用python软件进行分析、《计算 机程序设计》课程使用 $\mathrm{C}++$ 或 $\mathrm{C} \#$ 等软件进行开发, 《计量经济学》运用stata或spss软件进行量 化分析、《数据库管理系统》采用 SQL Server数据库、《物流信息系统》课程结合唯智软件 展开、《物流与信息技术》课程依托RFID实验室进行演示、《物流系统仿真》课程使用Flexsim 和plant simulation软件进行模拟、《运筹学》课程运用lingo软件、《项目管理》课程采用Microsoft Project软件等进行教学, 并引导学生上机操作。

\subsection{2案例教学}

案例教学是一种通过模拟或者重现工作中的一些情境, 让学生深入了解案例场景, 通过 讨论或者PPT展示的形式进行考核, 提高学生解决问题的能力。物流管理专业的绝大部分专 业课程都可以采用案例教学的方式展开, 例如, 创新创业管理、供应链管理案例研究、管理 决策工具、物流成本管理等。

\subsection{3项目调研}

通过与企业的合作，企业委托物流管理专业教师进行项目研究，或开展横向课题，或是 学校和企业建立物流和供应链研发中心, 搭建实习调研平台, 由物流管理专业教师负责, 让 学生参与项目的具体运作, 通过接触实际的项目, 让学生去企业或政府部门收集资料, 分析 存在的问题, 最终形成解决方案, 以此提高学生的实际动手能力。

3.2.4课程实习

课程实习主要是与课堂教学相结合的, 每个学期, 可根据课堂教学的需要安排课程实习, 例如, 《物流设施与设备》、《生产计划和控制》、《仓储和库存管理》等课程的部分教学 活动可以安排在相关的企业进行, 通过与企业一线员工交流学习, 提高学生适应工作岗位的 能力。

\subsubsection{CO-OP实习}

通过与多家单位长期合作，可以尝试建立CO-O合作机制，根据合作单位的需求，选派大 二和大三优秀学生进入企业实习，企业委派专业人员进行指导，并对实习效果进行考核，实 习结果与课程学分对接, 让物流管理专业学生获得更多的实习锻炼的机会。

\subsection{6第二课堂}

鼓励学生积极参与学术科研、学术竞赛、社会实践, 以及各类创新创业活动。例如, 参 与“工业4.0”智能工厂研究，物流的干线、支线领域、落地环节和管控环节的创业研究以及“互 联网+智能物流”的研究等; 同时, 参与“挑战杯”、“互联网+”大学生创新创业大赛、“创青春” 
创业实践挑战赛和大学生创新创业计划项目等赛事, 各项比赛和活动可转换为课程学分, 提 高学生的创新创业意识和能力。

\section{3教学方法的改进}

教学方法作为教师达成教育目的的手段, 是一种复杂的、动态发展的概念。 ${ }^{[8]}$ 大量学者 对物流教学方法进行了研究, Gravier和Farris对物流教学方法进行了全面的论述 ${ }^{[9]}$ 。Huang等 调查发现可持续相关课程的教学方法中, 排名前 5 的方法主要有: 案例研究、课程讨论、布置 作业、教科书讲授和演讲。 ${ }^{[3]}$ Rogers和Braziotis通过向17个国家的教授发放匿名问卷，收集到 最有效的教学方法依次是：案例研究和课堂讨论。未来的教学方法主要集中在：基于虚拟现 实的模拟和工业实践。[10]

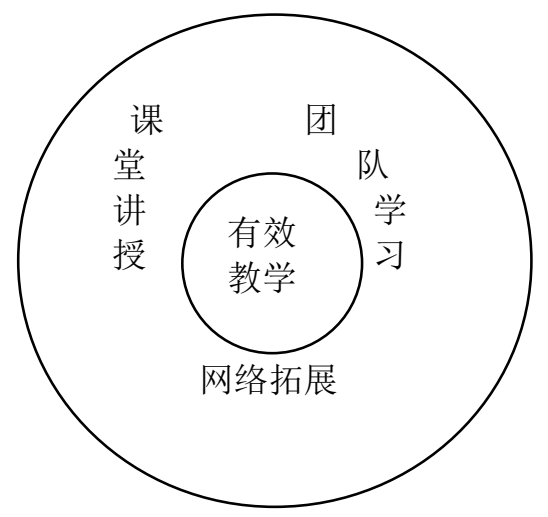

图2 物流管理专业的教学方法

物流管理专业各种教学方法追求的目标是有效教学, 达到教师有效地教, 学生有效地学, 做到教学相长。主要采用三种模式实现, 即课堂讲授、团队学习和网络拓展。如图2所示。

\subsection{1课堂讲授}

课堂讲授要求教师课前准备充分, 收集行业最新动态和热点问题。通过教师和学生面对 面沟通, 对问题的阐述简练准确, 深入浅出, 思路清晰, 重、难点突出。教师对课程内容熟 练, 能够理论联系实际。注意启发学生思考和联想, 给学生以启迪。通过提问等形式进行互 动, 调动学生学习的积极性。课余布置个人作业, 巩固教学效果。

3.3.2团队学习

团队学习注重构建学习型组织, 发挥团队的协作和组织能力。各门专业必修课和专业选 修课在新学期开始阶段, 可以让学生自由组队或采取教师指定的形式分成学习小组, 随着课 程的深入, 以小组的为单位完成各项任务, 例如, 开展啤酒游戏、进行沙盘模拟、小组调研、 案例优化方案设计以及编制创业计划书等, 要求各小组制作PPT并上台汇报成果, 评价时每 一个小组分配一份评分表, 该表主要由演讲内容、演讲表现和提问环节三部分构成, 各部分 的比重依次是 $40 \%$ 、 $40 \%$ 和 $20 \%$, 在汇报的提问环节，鼓励其他小组的同学积极提问，由汇报 小组的成员回答, 并对提问和回答问题的同学进行奖励。各个小组给其他组评定分数, 主讲 教师也进行相应的评分。另外, 要求组长结合各组员的表现给定成员的分数, 主讲教师最后 结合各小组的评分和教师的评分进行最终的评判。团队学习形式将主动权交给学生, 各小组 长负责任务的协调和实施, 组员之间共同学习, 共同成长。同时, 在PPT汇报和提问环节, 学生们进行激烈的讨论, 有效激发了学生的学习热情, 锻炼了学生的团队协作能力、口头表 达能力和逻辑思维能力。

\subsection{3网络拓展}

网络拓展即进行智慧化教学, 可以采用多种形式将信息技术与物流课程教学深度融合, 逐渐向以学为中心、能力培养为主以及多种学习方式转变, 可以采取开设慕课、微课、翻转 课堂等方式, 利用雨课堂、优芽网等技术支持课堂教学, 改进教学的方式方法。 


\section{4. 结束语}

通过分析经济、环境和政策的现状，结合国内外学者对物流管理专业课程研究的情况， 基于可持续理念, 从课程体系的设计、实践教学体系的构建和教学方法的改进等三个方面, 提出了本科物流管理专业课程体系的构建方案, 期望对物流管理相关专业教学计划和培养方 案提供决策参考。

\section{References}

[1] Key points of the Ministry of education in 2017 [EB/OL]. http://www.moe.edu.cn/jyb_xwfb/ moe_164/201702/t20170214_296203.html

[2] FIGUEIRO P S, RAUFFLET E. Sustainability in higher education: a systematic review with focus on management education [J]. Journal of Cleaner Production, 2015, 106:22-33.

[3] WU Y-C J, HUANG S, KUO L, et al. Management education for sustainability: A web-based content analysis [J]. Academy of Management Learning \& Education, 2010, 9(3): 520-531.

[4] LUTZ H, BIROU L. Logistics education: a look at the current state of the art and science [J]. Supply Chain Management: An International Journal, 2013, 18(4): 455-467.

[5] JIM WU Y-C, KEVIN HUANG S, GOH M, et al. Global logistics management curriculum: perspective from practitioners in Taiwan [J]. Supply Chain Management: An International Journal, 2013, 18(4): 376-388.

[6] YEW WONG C, B. GRANT D, ALLAN B, et al. Logistics and supply chain education and jobs: a study of UK markets [J]. The International Journal of Logistics Management, 2014, 25(3): 537-552.

[7] GARTNER. Survey Analysis: Top 25 North American Supply Chain Undergraduate University Programs,2016[EB/OL].

http://www.business.rutgers.edu/sites/default/files/user_files/about/rankings-supply-chain-unde rgraduate-gartner-2016

[8] Zhong Qiquan. Teaching Methods: The Concept Interpretation [J]. Educational Research, 2017, (01): 95-105.

[9] WALLER M, GRAVIER M J, THEODORE FARRIS M. An analysis of logistics pedagogical literature: past and future trends in curriculum, content, and pedagogy [J]. The International Journal of Logistics Management, 2008, 19(2): 233-253.

[10]ROGERS H, BRAZIOTIS C. Current Issues in Teaching Logistics Management [M]. Dynamics in Logistics. Springer. 2016. 